\title{
2-18 F-Fluoropropionic Acid as a PET Imaging Agent for Prostate Cancer
}

NagaVaraKishore Pillarsetty, Blesida Punzalan, and Steven M. Larson

Department of Radiology, Memorial Sloan-Kettering Cancer Center, New York, New York

There is a high interest in developing an ${ }^{18} \mathrm{~F}$-labeled PET tracer that can aid in diagnosis and therapy monitoring of prostate cancer. In the current study, we have evaluated the potential of $2-{ }^{18} \mathrm{~F}$-fluoropropionic acid $\left({ }^{18} \mathrm{~F}-\mathrm{FPA}\right)$ as a PET tracer for imaging prostate cancer. Methods: ${ }^{18}$ F-FPA was synthesized starting from methyl-2-bromopropionate. Small-animal PET studies were performed on mice with CWR22rv1, PC-3, DU-145, and LNCaP prostate xenografts, and comparison of imaging characteristics of ${ }^{18} \mathrm{~F}-\mathrm{FPA}$ with ${ }^{18} \mathrm{~F}-\mathrm{FDG}$ uptake is reported. Biodistribution studies with ${ }^{18} \mathrm{~F}-\mathrm{FPA}$ were performed on mice with CWR22rv1 xenografts and compared with ${ }^{14} \mathrm{C}$-acetate. Results: ${ }^{18} \mathrm{~F}-\mathrm{FPA}$ was synthesized in $44 \%$ overall radiochemical yield (decay-corrected). Small-animal PET studies revealed that ${ }^{18} \mathrm{~F}-$ FPA can delineate both androgen-dependent and androgenindependent prostate xenografts with high tumor-to-background ratios. Comparative imaging studies demonstrate the superior performance of ${ }^{18} \mathrm{~F}-\mathrm{FPA}$ over ${ }^{18} \mathrm{~F}-\mathrm{FDG}$ for imaging prostate cancer, with excellent tumor-to-background contrast. Biodistribution studies show that tumor uptake of the tracer was $5.52 \pm$ $0.35,5.53 \pm 0.42,5.74 \pm 0.54$, and $5.34 \pm 0.19$ percentage injected dose (\%ID) per gram at $1,2,3$, and $4 \mathrm{~h}$, respectively, after injection. The $\%$ ID/g values for ${ }^{18} \mathrm{~F}-\mathrm{FPA}$ and ${ }^{14} \mathrm{C}$-acetate $1 \mathrm{~h}$ after tail vein injection were $7.08 \pm 0.80$ and $0.36 \pm 0.08$ in tumor, and the corresponding tumor-to-muscle ratios were 1.94 and 2.06 , respectively. Conclusion: The data presented here indicate that ${ }^{18} \mathrm{~F}$-FPA accumulates in prostate cancers with high tumorto-background ratios. ${ }^{18} \mathrm{~F}$-FPA has potential for use in the clinical diagnosis of prostate cancer in humans.

Key Words: prostate cancer; PET; ${ }^{11} \mathrm{C}$-acetate; $2-{ }^{18} \mathrm{~F}-$ fluoropropionic acid; CWR22rv1

J Nucl Med 2009; 50:1709-1714

DOI: 10.2967/jnumed.109.064212

$\mathbf{P}$ rostate cancer is the most commonly diagnosed and second leading cause of cancer deaths in men in the United States ( 1 ). If detected early, prostate cancer treatment is highly successful, but at present there are no known treatments for advanced metastatic disease. For primary prostate tumors, determining the precise location and defining the target are critical for defining the clinical target volume for conformal radiotherapy (2). The field of noninvasive molec-

Received Mar. 12, 2009; revision accepted Jun. 23, 2009.

For correspondence or reprints contact: NagaVaraKishore Pillarsetty, 1275 York Ave., Box 394 New York, NY 10065.

E-mail: pillarsn@mskcc.org

COPYRIGHT () 2009 by the Society of Nuclear Medicine, Inc. ular imaging using PET isotopes has made rapid advances for the detection of primary and metastatic tumors, with ${ }^{18} \mathrm{~F}$-FDG leading the way as a universal tumor-imaging agent. However, for prostate cancer, the results with ${ }^{18} \mathrm{~F}-$ FDG have been suboptimal (3). Hence, there is an urgent need to develop PET agents that can be used for routine detection and characterization of prostate tumors. Both ${ }^{11} \mathrm{C}$ and ${ }^{18} \mathrm{~F}$-labeled radiotracers have been developed, including ${ }^{11} \mathrm{C}$-acetate, ${ }^{11} \mathrm{C}$-choline, ${ }^{18} \mathrm{~F}$-fluoroacetate $(4,5)$, and ${ }^{18} \mathrm{~F}$-fluoroethylcholine (6-9), among others. ${ }^{11} \mathrm{C}$-acetate has shown promising results for the diagnosis of primary and metastatic prostate cancer, but the short half-life of ${ }^{11} \mathrm{C}(20$ min) means that ${ }^{11} \mathrm{C}$ tracers can be used only at facilities that have an on-site cyclotron. ${ }^{11} \mathrm{C}$ is impractical for use as a routine PET tracer in many imaging centers. ${ }^{18} \mathrm{~F}$-labeled agents offer practical benefits due to a relatively long halflife $(110 \mathrm{~min})$. In this regard, ${ }^{18} \mathrm{~F}$-fluoroacetate $(4,5)$ and ${ }^{18} \mathrm{~F}$-fluorine derivatives of choline (6-9) are currently being investigated as prostate tumor-imaging agents. ${ }^{18} \mathrm{~F}$-fluoroacetate is a substrate for acetyl coenzyme A synthase and hence mimics ${ }^{11} \mathrm{C}$-acetate in the primary steps and has been proposed as a useful alternative for prostate cancer imaging. ${ }^{18} \mathrm{~F}$-fluoroethylcholine mimics choline that is trapped inside the cells after phosphorylation by choline kinase, which is overexpressed in tumor cells. So far, no clear winner has emerged for prostate cancer.

In our continuing effort to identify novel PET tracers for oncologic applications $(10-13)$, we have identified $2-{ }^{18} \mathrm{~F}-$ fluoropropionic acid $\left({ }^{18} \mathrm{~F}-\mathrm{FPA}\right)$ as a possible radiotracer for imaging prostate cancer. The hypothesis is that ${ }^{18} \mathrm{~F}-\mathrm{FPA}$ would mimic acetate in vivo in the same way that fluoroacetate mimics acetate $(14,15)$ and hence would accumulate in prostate cancer and allow tumor delineation by PET. In support of this hypothesis, we present preliminary data including biodistribution and PET studies with ${ }^{18} \mathrm{~F}-$ FPA. The results suggest the potential use of ${ }^{18} \mathrm{~F}-\mathrm{FPA}$ as a new PET radiotracer for imaging prostate cancer and provide a rationale for further laboratory and clinical characterization of this tracer.

\section{MATERIALS AND METHODS}

All reagents and solvents were purchased from either Aldrich Chemical Co. or Fisher Scientific and, unless stated otherwise, were used without further purification. All high-performance 
liquid chromatography (HPLC) solvents were filtered $(0.45 \mu \mathrm{m}$, nylon, Alltech) before use. Water (ultrapure, ion-free, $>18.2$ $\mathrm{M} \Omega \cdot \mathrm{cm}^{-1}$ ) was obtained from a Millipore $\alpha$-Q Ultra-pure water system. HPLC was performed using a Shimadzu system equipped with a C-18 reversed-phase column (Phenomenex Luna analytic $4.6 \times 250 \mathrm{~mm}$ or SemiPrep $21.2 \times 100 \mathrm{~mm}, 5 \mu \mathrm{m}, 1.0$ or $6.0 \mathrm{~mL} /$ min, $0.2 \%$ acetic acid/ $\left.\mathrm{CH}_{3} \mathrm{CN}\right), 2$ LC-10AT pumps, an SPDM10AVP photodiode array detector, and a BioScan Flow Count PIN diode radiodetector. Radioactivity was assayed using a Capintec CRC-15R dose calibrator.

No-carrier-added ${ }^{18} \mathrm{~F}$-fluoride ion was produced by the ${ }^{18} \mathrm{O}(p, n){ }^{18} \mathrm{~F}$ nuclear reaction by bombardment of an enriched ${ }^{18} \mathrm{O}-\mathrm{H}_{2} \mathrm{O}$ target with $11-\mathrm{MeV}$ protons using an EBCO TR-19/9 cyclotron.

\section{Synthesis of ${ }^{18} \mathrm{~F}-\mathrm{FPA}$}

${ }^{18} \mathrm{~F}-\mathrm{FPA}$ was synthesized using an established procedure (Scheme 1) (16). Briefly, ${ }^{18}$ F-fluoride ion $(2.8 \mathrm{GBq}=75 \mathrm{mCi})$ in water was added to a vial containing $80 \mu \mathrm{L}$ of $0.25 \mathrm{M}$ potassium carbonate and $13 \mathrm{mg}$ of Kryptofix dissolved in $1 \mathrm{~mL}$ of acetonitrile. Water was removed azeotropically with acetonitrile $(3 \times 1 \mathrm{~mL})$ at $80^{\circ} \mathrm{C}$. To the anhydrous ${ }^{18} \mathrm{~F}-\mathrm{KF} / \mathrm{K}_{2} \mathrm{CO}_{3}$ complexed with Kryptofix was added a solution of methyl-2D,L-bromopropionate $(3 \mathrm{mg}$ ) in $300 \mu \mathrm{L}$ of anhydrous acetonitrile, and the vial was sealed and heated at $80^{\circ} \mathrm{C}$ for $6 \mathrm{~min}$ to give methyl-2- ${ }^{18} \mathrm{~F}$-fluoropropionate. The vial was allowed to cool to room temperature and diluted with $700 \mu \mathrm{L}$ of water and purified using HPLC. The intermediate was purified on a semipreparative Phenomenex reversed-phase C-18 column (Gemini-NX, $100 \times$ $21.2 \mathrm{~mm}, 5 \mu \mathrm{m}, 110 \mathrm{~A}$ ) using a mixture of $0.2 \%$ aqueous acetic acid:acetonitrile (60:40) as the eluant, with a flow rate of $6 \mathrm{~mL} /$ $\min$. The product methyl-2- ${ }^{18} \mathrm{~F}$-fluoropropionate, with a retention time of $5.4 \mathrm{~min}$, was collected. To the product, $50 \mu \mathrm{L}$ of $10 \mathrm{~N}$ sodium hydroxide was added and heated at $80^{\circ} \mathrm{C}$ for $10 \mathrm{~min}$ to give sodium $2-{ }^{18} \mathrm{~F}$-fluoropropionate. The solvent was removed under reduced pressure, and the residue was neutralized with $85 \mu \mathrm{L}$ of $6 \mathrm{~N} \mathrm{HCl}$. The product was formulated in $0.9 \%$ saline and used for studies. For analysis of purity, $40 \mu \mathrm{L}$ of product were acidified with $10 \mu \mathrm{L}$ of $10 \mathrm{~N} \mathrm{HCl}$ and passed through a reversedphase $\mathrm{C}-18$ column (Luna, $250 \times 4.6 \mathrm{~mm}, 5 \mu, 100 \mathrm{~A}$ ) using $0.2 \%$ aqueous acetic acid as the eluting solvent, with a flow rate of $1 \mathrm{~mL} / \mathrm{min}$. The final radiochemical yield was around $44 \% \pm 3 \%$ (nonoptimized), with a specific activity of around $50 \mathrm{GBq} / \mu \mathrm{M}$.

\section{Octanol-Water Partition Coefficient Study (logP)}

Octanol-water partition coefficients were determined for ${ }^{18} \mathrm{~F}$ FPA at 4 different $\mathrm{pH}$ values - 6.4, 7.0, 7.4, and 8.4-by measuring the distribution of radiolabeled compound in 1-octanol and phosphate-buffered saline. A $20 \mu \mathrm{L}$ sample of ${ }^{18}$ F-FPA $(\sim 10-20 \mu \mathrm{Ci})$ in saline was added to a vial containing $5 \mathrm{~mL}$ each of 1 -octanol and phosphate-buffered saline. After being stirred in a vortex mixer for $1 \mathrm{~min}$, the vial was centrifuged for $5 \mathrm{~min}$ to ensure complete separation of layers. Five hundred microliters of each layer were taken in a preweighed vial, and ${ }^{18} \mathrm{~F}$ counts (400- to $550-\mathrm{keV}$ energy range) were measured using a $\gamma$-counter (PerkinElmer 1480 Wizard 3 Auto $\gamma$-counter). Counts per unit weight of sample were calculated, and $\log \mathrm{P}$ values were calculated using the following formula:

$\log _{10} \mathrm{P}=\log _{10}$ (counts in $1 \mathrm{~mL}$ of octanol/counts in $1 \mathrm{~mL}$ of water).

\section{Generation of Tumor Xenografts}

All animal experiments were conducted in accordance with protocols approved by the Institutional Animal Care and Use Committee of Memorial Sloan-Kettering Cancer Center and followed National Institutes of Health guidelines for animal welfare. Tumor cell lines were obtained from the American Type Culture Collection and cultured under conditions provided by the supplier. The cell lines included CWR22rv1, PC-3, LNCaP, and DU-145. Subcutaneous tumors were produced in nude mice (20-25 g; Taconic) by subcutaneous injection of $5 \times 10^{6}$ tumor cells in $200 \mu \mathrm{L}$ consisting of $100 \mu \mathrm{L}$ of cell culture medium and $100 \mu \mathrm{L}$ of Matrigel (BD Biosciences) under 2\% isoflurane anesthesia on the right forelimb of mice.

\section{Small-Animal PET}

Imaging was performed by use of a dedicated small-animal PET scanner (Focus 120 microPET; Siemens Medical Solutions USA, Inc.). The mice were maintained under $2 \%$ isoflurane anesthesia in oxygen at $2 \mathrm{~L} / \mathrm{min}$ during the entire scanning period. Imaging was performed $1 \mathrm{~h}$ after administration of $11.1 \mathrm{MBq}(300$ $\mu \mathrm{Ci}$ ) of either ${ }^{18} \mathrm{~F}-\mathrm{FPA}$ or ${ }^{18} \mathrm{~F}$-FDG via injection in the tail vein. For a comparative study, mice were kept fasting for $4 \mathrm{~h}$ and imaged with ${ }^{18} \mathrm{~F}$-FDG $1 \mathrm{~h}$ after intravenous injection. The activity was allowed to decay for $24 \mathrm{~h}$, and then the mice were administered ${ }^{18} \mathrm{~F}$-FPA via the tail vein and imaged $1 \mathrm{~h}$ after injection. An energy window of 350-700 keV and a coincidence timing window of $6 \mathrm{~ns}$ were used. The image data were corrected for nonuniformity of the scanner response, dead-time count losses, and physical decay to the time of injection. No correction was applied for attenuation, scatter, or partial-volume averaging. The measured reconstructed spatial resolution of the Focus 120 scanner is approximately $1.6 \mathrm{~mm}$ in full width at half maximum at the center of the field of view. The counting rates in the reconstructed images were converted to activity concentrations (percentage injected dose [\%ID] per gram of tissue) by use of a system calibration factor derived from the imaging of a mouse-sized waterequivalent phantom containing ${ }^{18} \mathrm{~F}$.

\section{In Vivo Biodistribution Studies}

For single-isotope $\left({ }^{18} \mathrm{~F}\right)$ biodistribution studies, mice with CWR22rv1 tumors were injected in the tail vein with 3.7-5.5 $\mathrm{MBq}(100-150 \mu \mathrm{Ci})$ of ${ }^{18} \mathrm{~F}-\mathrm{FPA}$ in $200 \mu \mathrm{L}$ of saline. Radioactivity in the syringe before and after administration was measured in an energy-calibrated dose calibrator (CRC-15R), and the exact quantity received by each animal was determined. The animals were euthanized at different time points, and then the organs

SCHEME 1. Synthesis of ${ }^{18}$ F-FPA.

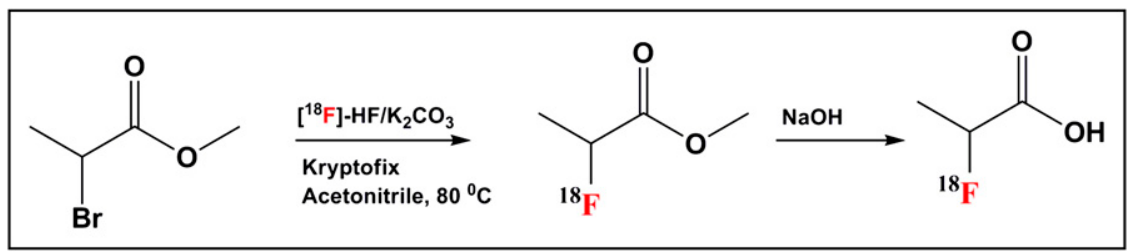


were harvested. ${ }^{18} \mathrm{~F}$ radioactivity was measured in a calibrated $\gamma$-counter (1480 Wizard 3 Auto $\gamma$-counter) using a 400- to 600$\mathrm{keV}$ energy window and decay correction. The counts were converted into activity, and \% ID/g was calculated by dividing by decay-corrected injected activity and weight of the organ. For dual-isotope biodistribution studies, each animal was administered $200 \mu \mathrm{L}$ of saline containing $3.7 \mathrm{MBq}$ of ${ }^{18} \mathrm{~F}-\mathrm{FPA}$ and about $0.0037 \mathrm{MBq}(0.1 \mu \mathrm{Ci})$ of ${ }^{14} \mathrm{C}$-acetate. Initially, ${ }^{18} \mathrm{~F}$ radioactivity was measured in a calibrated $\gamma$-counter (1480 Wizard 3 Auto $\gamma$-counter) using a 400- to 600-keV energy window and decay correction. For measuring ${ }^{14} \mathrm{C}$ activity, all samples were solubilized (Soluene-350, Packard Instrument Co., Inc.) after the ${ }^{18} \mathrm{~F}$ radioactivity counting. The samples were then stored at $4^{\circ} \mathrm{C}$ for $1 \mathrm{~d}$ to allow for ${ }^{18} \mathrm{~F}$ decay. A scintillant agent (Insta-Fluor; Packard Instrument Co., Inc.) was added to solubilized samples, and ${ }^{14} \mathrm{C}$ radioactivity was determined by liquid scintillation counting (TriCarb Liquid Scintillation Analyzer, model 1600TR; Packard Instrument Co., Inc.) using external standard quench corrections. The counts were converted into activity, and \% ID/g was calculated by dividing by decay-corrected injected activity and the weight of the organ. For each time point, a minimum of 3 animals was used for the study, and the values are reported as mean \pm SD of mean. The Student $t$ test was performed, and differences were considered statistically significant at $P<0.05$.

\section{RESULTS}

\section{Synthesis}

The overall synthesis time for ${ }^{18} \mathrm{~F}-\mathrm{FPA}$ was $45 \mathrm{~min}$, and the average radiochemical yields were about $44 \% \pm 3 \%$ (decay-corrected). The radiochemical purity was at least $98 \%$. The average specific activity was $50 \mathrm{GBq} / \mu \mathrm{M}$.

\section{Octanol-Water Partition Coefficient Study (logP)}

Lipophilicity $\log \mathrm{P}$ values of ${ }^{18} \mathrm{~F}-\mathrm{FPA}$ at $\mathrm{pH} 6.4,7.0,7.4$, and 8.4 are $-2.89 \pm 0.02,-3.08 \pm 0.04,-2.97 \pm 0.13$, and $-3.07 \pm 0.03$, respectively. As expected, for small carboxylic acids the $\log \mathrm{P}$ is very low, indicating that the compound is very hydrophilic. The lipophilicity is not sensitive to changes in $\mathrm{pH}$ within the measured physiologically relevant $\mathrm{pH}$ ranges.

\section{Small-Animal PET}

Small-animal PET was performed to evaluate the potential of ${ }^{18}$ F-FPA as a tumor-imaging agent in mice with prostate cancer CWR22rv1 xenografts. Figure 1 shows a small-animal PET image of 2 mice $1 \mathrm{~h}$ after administration of ${ }^{18} \mathrm{~F}$-FPA via the tail vein. The acquisition time was $5 \mathrm{~min}$. As shown in Figure 1, the CWR22rv1 tumor is clearly delineated with ${ }^{18} \mathrm{~F}$-FPA. Uptake in the tumor at $1 \mathrm{~h}$ after administration was $4.4 \% \mathrm{ID} / \mathrm{g}$. In addition to the tumor, the heart and brain showed high uptake. The corresponding uptake values in the heart and brain were 4.0 and $4.6 \% \mathrm{ID} / \mathrm{g}$.

Figure 2 shows small-animal PET images of mice bearing CWR22rv1 tumor xenografts, imaged with ${ }^{18} \mathrm{~F}$-FPA and ${ }^{18}$ F-FDG. First, the mice were kept fasting for $4 \mathrm{~h}$, and then ${ }^{18} \mathrm{~F}-\mathrm{FDG}$ was administered via the tail vein and imaged $1 \mathrm{~h}$ after administration. The activity was allowed to decay for $24 \mathrm{~h}$, and the same mice were imaged with ${ }^{18} \mathrm{~F}$-FPA $1 \mathrm{~h}$

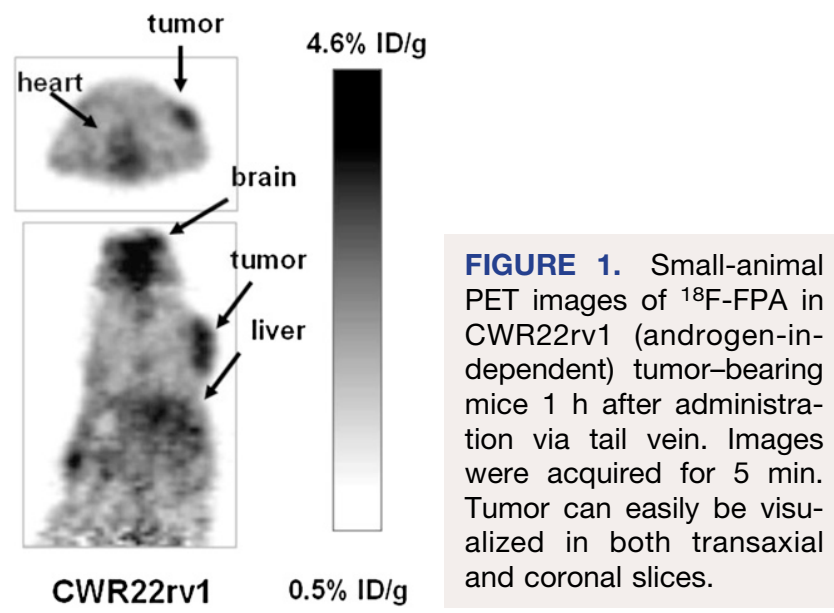

after injection. In the case of ${ }^{18} \mathrm{~F}-\mathrm{FPA}$, the animals were not fasting. As shown in Figure 2, the tumors can be readily visualized with ${ }^{18} \mathrm{~F}-\mathrm{FPA}$, giving increased uptake and tumor contrast in comparison to ${ }^{18} \mathrm{~F}-\mathrm{FDG} .{ }^{18} \mathrm{~F}-\mathrm{FPA}$ is taken up by the brain and kidneys but much less so than is ${ }^{18} \mathrm{~F}$ FDG. Figure 3 shows small-animal PET images of mice with different xenografts of prostate cancer origin. DU-145 is a cell line derived from brain metastases of prostate cancer and is androgen-independent. PC-3 is a highly metastatic androgen-independent cancer cell line derived from bone metastases. LNCaP is an androgen-sensitive cell line derived from lymph node metastases. It is apparent from PET studies that ${ }^{18} \mathrm{~F}$-FPA shows a high accumulation in various tumor xenografts, and tumors can be clearly visualized because of a high tumor-to-background ratio.

\section{In Vivo Biodistribution}

The in vivo biodistribution profile of ${ }^{18} \mathrm{~F}-\mathrm{FPA}$ at $1,2,3$, and $4 \mathrm{~h}$ after administration via the tail vein in nude mice
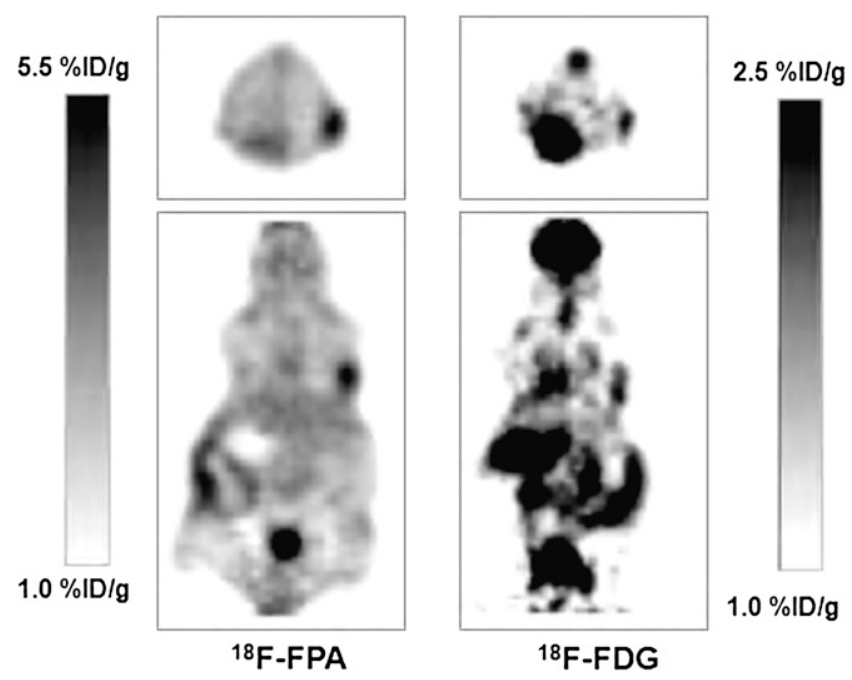

FIGURE 2. Small-animal PET images of nude mice with CWR22 xenografts imaged with either ${ }^{18} \mathrm{~F}-\mathrm{FPA}$ or ${ }^{18} \mathrm{~F}-\mathrm{FDG}$ $1 \mathrm{~h}$ after tail vein injection. 


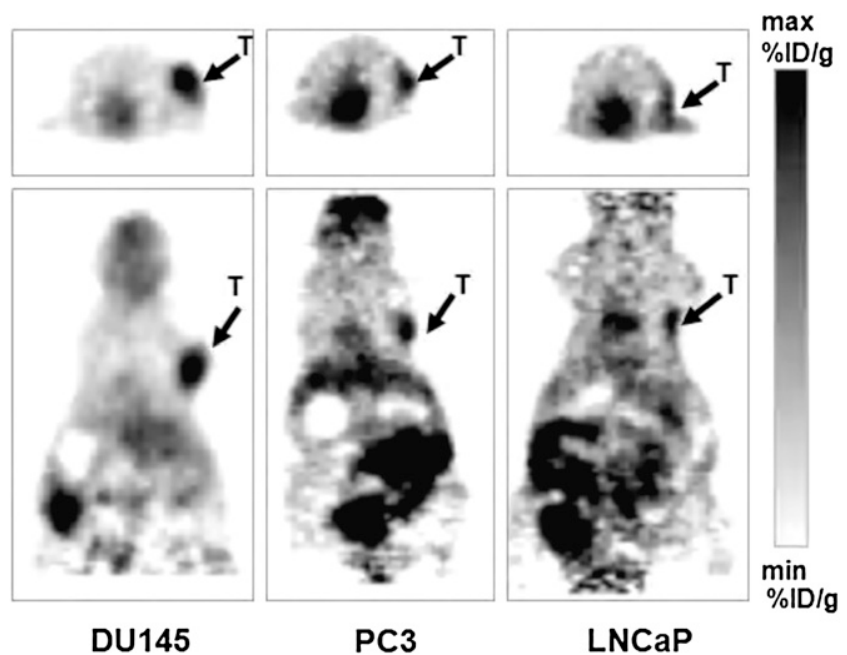

FIGURE 3. Small-animal PET images of nude mice with DU-145, PC3, and LNCaP xenografts imaged with ${ }^{18} \mathrm{~F}-\mathrm{FPA}$ $1 \mathrm{~h}$ after tail vein injection. Minimum and maximum values in small-animal PET images for DU-145, PC3, and LNCaP are 1.2 and $3.8,1.5$ and 3.8 , and 2.0 and 4.0 , respectively.

with CWR22 xenografts is shown in Figure 4. It is apparent from these data that biodistribution remains constant throughout the study. There is considerable accumulation of tracer in tumor. Tumor uptake of the tracer was $5.52 \pm$ $0.35,5.53 \pm 0.42,5.74 \pm 0.54$, and $5.34 \pm 0.19 \% \mathrm{ID} / \mathrm{g}$ at $1,2,3$, and $4 \mathrm{~h}$, respectively, after injection. In addition to tumor, blood and heart showed high activity. Figure 5 shows the tumor-to-organ ratio of ${ }^{18} \mathrm{~F}$-FPA at $1,2,3$, and 4 $\mathrm{h}$ after injection. The tumor-to-organ ratio is greater than 1 for most of the organs with the exception of the heart, which is around 0.95 .

\section{Comparison with ${ }^{14} \mathrm{C}$-Acetate}

To compare the efficacy of ${ }^{18}$ F-FPA with acetate, we performed biodistribution studies $1 \mathrm{~h}$ after simultaneous administration of ${ }^{18} \mathrm{~F}-\mathrm{FPA}$ and ${ }^{14} \mathrm{C}$-acetate via the tail vein (Table 1). The \% ID/g values for ${ }^{18} \mathrm{~F}-\mathrm{FPA}$ and ${ }^{14} \mathrm{C}$-acetate in tumor were $7.08 \pm 0.80$ and $0.36 \pm 0.08$, respectively, and the corresponding tumor-to-muscle ratios were 1.94 and 2.06 , respectively. Two important points to note from the data are that the $\% \mathrm{ID} / \mathrm{g}$ values were much higher for ${ }^{18} \mathrm{~F}$-FPA than for ${ }^{14} \mathrm{C}$-acetate and that the ratio of this type of tumor to some organs was more favorable for ${ }^{18} \mathrm{~F}-\mathrm{FPA}$ than for ${ }^{14} \mathrm{C}$-acetate. The biodistribution values obtained with ${ }^{14} \mathrm{C}$ acetate agreed well with ${ }^{11} \mathrm{C}$-acetate data in the literature (5).

\section{DISCUSSION}

The suboptimal performance of ${ }^{18} \mathrm{~F}-\mathrm{FDG}$ for selective and sensitive detection of prostate tumors has spurred research in the development of alternative PET agents for detection of prostate cancers. ${ }^{11} \mathrm{C}$-acetate was initially developed as a PET tracer to measure myocardial metabolism $(17,18)$ but was also found to be effective in detecting prostate tumors (19). Studies on the mechanism suggest a role for fatty acid synthase, which uses acetate as its substrate for the synthesis of long-chain fatty acids. Therefore, the increased uptake of ${ }^{11} \mathrm{C}$-acetate observed in prostate tumors has been attributed to fatty acid synthase activity (20). Despite the success of ${ }^{11} \mathrm{C}$-acetate for diagnosing prostate tumors, the short halflife of ${ }^{11} \mathrm{C}$ is a problem for its use as a routine PET agent. In contrast, ${ }^{18} \mathrm{~F}$-labeled tracers are advantageous because their relatively long half-life $(2 \mathrm{~h})$ does not require an onsite cyclotron.

Long-chain carboxylic acids labeled with ${ }^{18} \mathrm{~F}$ have been investigated as cardiac imaging agents for measuring myocardial uptake (21). To our knowledge, no such studies have been reported for short-chain carboxylic acids. ${ }^{18} \mathrm{~F}$-FPA was initially developed as a radioderivatization agent for labeling small peptides with ${ }^{18} \mathrm{~F}$ (16). For example, the new radiotracer ${ }^{18} \mathrm{~F}$-galacto-RGD, which is currently under clinical trials for imaging $\alpha_{\mathrm{v}} \beta_{3}$ integrin expression, uses
FIGURE 4. Biodistribution profile of ${ }^{18} \mathrm{~F}-\mathrm{FPA}$ in nude mice with CWR22rv1 xenografts at $1,2,3$, and $4 \mathrm{~h}$ after tail vein injection. Values are mean $\pm S D$ of mean ( $n=3$ for each time point). Lg. $=$ large; Sm. = small.

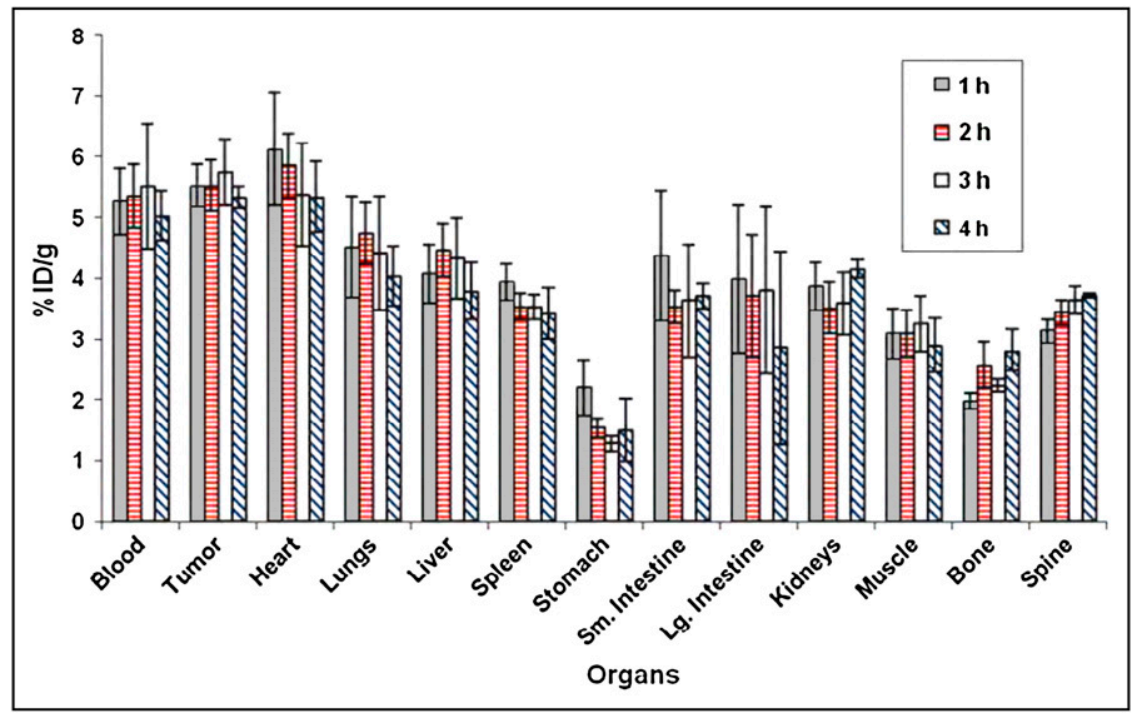




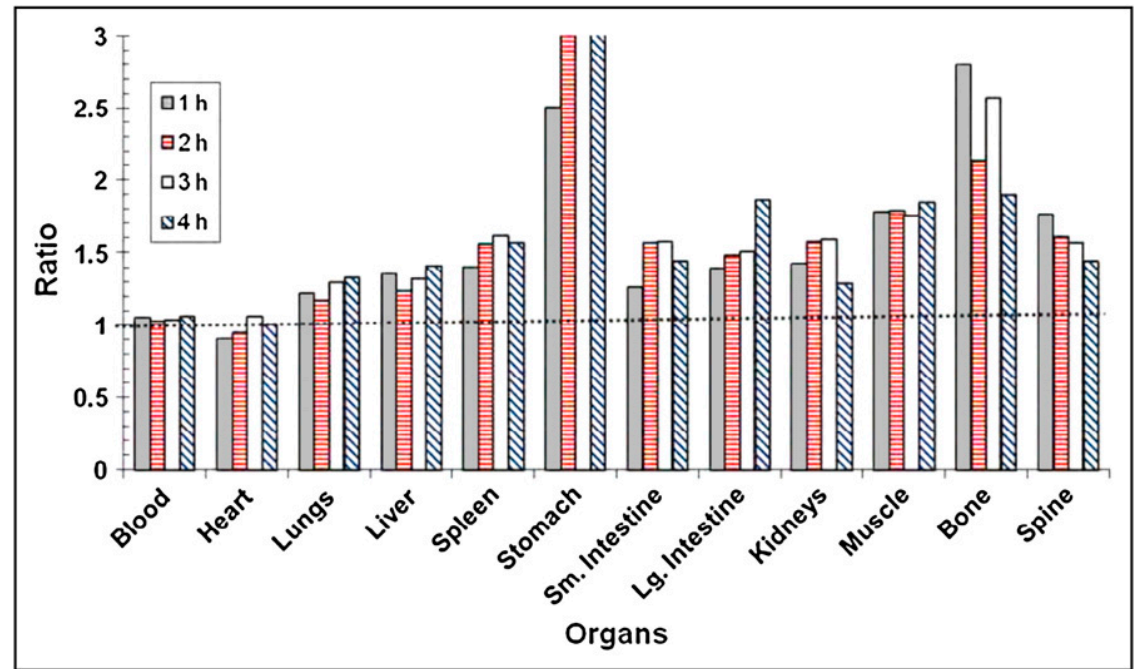

FIGURE 5. Tumor-to-organ ratio of ${ }^{18} \mathrm{~F}-\mathrm{FPA}$ in nude mice with CWR22rv1 xenografts at $1,2,3$, and $4 \mathrm{~h}$ after tail vein injection. $\mathrm{Lg}$. = large; Sm. = small.
${ }^{18} \mathrm{~F}$-FPA as the prosthetic group for radiolabeling the peptide (22). The biodistribution and imaging properties of ${ }^{18} \mathrm{~F}-\mathrm{FPA}$ itself have not been reported. Toxicologic studies in rats have shown that FPA caused no acute toxicity at $2.3 \mathrm{mmol} /$ $\mathrm{kg}$ (23). Sodium, potassium, and calcium salts of propionic acid are extensively used as food additives. Metabolic studies have indicated that propionate can be used as a precursor for synthesis of fatty acids, glycogen, amino acids, and others, depending on the species $(14,15,24)$.

${ }^{18} \mathrm{~F}$-FPA was synthesized using well-established procedures $(14,15)$. Because the radiochemical yields obtained were high $(44 \% \pm 3 \%$ decay-corrected), further optimization of the yield was not attempted. Though the HPLC profile during sample purification indicated that the fluorination reaction was almost quantitative, the $44 \%$ overall radiochemical yield represents losses during fluoride transfers and the HPLC step. During the removal of solvent after hydrolysis of the methyl ester, it was observed that neutralization must be performed after the removal because FPA is fairly volatile and a significant amount of compound can be lost during the process even at $45^{\circ} \mathrm{C}$. In addition, during analytic HPLC, the solution must be acidic $(\mathrm{pH}<4)$ because the ionized and neutral forms of FPA have fairly different retention times under the conditions used. If the $\mathrm{pH}$ of the injectant is greater than 4, 2 separate peaks are observed. FPA has a low molar extinction coefficient in the ultraviolet region, making accurate calculations of specific activity difficult using a standard ultraviolet detector. The specific activity calculations were based on a minimal detectable concentration of FPA. Routinely during analysis, no ultraviolet absorption peaks (mass peaks) were observed during HPLC after the purification of ${ }^{18} \mathrm{~F}$-FPA. Hence, in calculating the specific activity of ${ }^{18} \mathrm{~F}-\mathrm{FPA}$, it was assumed the mass amount of FPA was just below the detectable limit.

\section{TABLE 1. Comparative Biodistribution Studies of ${ }^{18} \mathrm{~F}-\mathrm{FPA}$ and ${ }^{14} \mathrm{C}$-Acetate in Mice}

\begin{tabular}{|c|c|c|c|c|}
\hline \multirow[b]{2}{*}{ Organ } & \multicolumn{2}{|c|}{$\%$ ID $/ g^{*}$} & \multicolumn{2}{|c|}{ Tumor-to-organ ratio } \\
\hline & ${ }^{18} \mathrm{~F}-\mathrm{FPA}$ & ${ }^{14} \mathrm{C}$-acetate & ${ }^{18} \mathrm{~F}-\mathrm{FPA}$ & ${ }^{14} \mathrm{C}$-acetate \\
\hline Blood & $6.88 \pm 0.64$ & $0.02 \pm 0.02$ & 1.03 & 16.91 \\
\hline Tumor ${ }^{\dagger}$ & $7.08 \pm 0.80$ & $0.36 \pm 0.08$ & 1.00 & 1.00 \\
\hline Heart & $5.46 \pm 0.63$ & $0.25 \pm 0.03$ & 1.30 & 1.44 \\
\hline Lungs & $4.00 \pm 0.26$ & $0.85 \pm 0.11$ & 1.77 & 0.42 \\
\hline Liver & $5.61 \pm 0.50$ & $0.67 \pm 0.17$ & 1.26 & 0.53 \\
\hline Spleen & $4.36 \pm 0.85$ & $0.68 \pm 0.16$ & 1.62 & 0.52 \\
\hline Stomach & $2.53 \pm 1.04$ & $0.77 \pm 0.42$ & 2.80 & 0.47 \\
\hline Small intestine & $4.37 \pm 1.15$ & $0.81 \pm 0.13$ & 1.62 & 0.44 \\
\hline Large intestine & $3.71 \pm 1.09$ & $0.56 \pm 0.20$ & 1.91 & 0.64 \\
\hline Kidneys & $4.17 \pm 0.60$ & $0.58 \pm 0.14$ & 1.70 & 0.62 \\
\hline Muscle & $3.66 \pm 0.50$ & $0.17 \pm 0.03$ & 1.94 & 2.06 \\
\hline Bone & $1.68 \pm 0.54$ & $0.29 \pm 0.11$ & 4.23 & 1.22 \\
\hline Brain & $5.57 \pm 0.33$ & $0.30 \pm 0.02$ & 1.27 & 1.17 \\
\hline
\end{tabular}


In vivo studies indicate that ${ }^{18} \mathrm{~F}$-FPA can successfully detect prostate tumor xenografts in mice. Biochemical studies are under way to investigate the exact mechanism of uptake of ${ }^{18} \mathrm{~F}$-FPA in prostate cancers. As shown in the PET images (Figs. 1-3) and biodistribution data (Figs. 4 and 5), the compound localizes in the tumor and is retained throughout $4 \mathrm{~h}$ of observation. In addition to tumor, the heart, brain, and bladder show a high amount of activity. ${ }^{18} \mathrm{~F}$-FPA primarily clears through urine, as bladder shows a high amount of activity in PET images, similar to that seen with ${ }^{18} \mathrm{~F}$-fluoroacetate or ${ }^{18} \mathrm{~F}$-fluoroethylcholine. Similar to ${ }^{18} \mathrm{~F}$-fluoroacetate, ${ }^{18} \mathrm{~F}$-FPA has a fairly constant activity in tumor, and except for bone, the tumor-to-organ ratios do not differ much at the 30-min and 2-h time points (5). Unlike ${ }^{18} \mathrm{~F}$-fluoroacetate, ${ }^{18} \mathrm{~F}$-FPA appears to show no evidence of defluorination, and both PET and biodistribution studies show low bone uptake.

At later time points, activity was localized in the lower part of the gut. This region of the intestines has been shown to be one in which absorption of small carboxylic acids occurs. In our comparative imaging study with ${ }^{18} \mathrm{~F}-\mathrm{FDG}$, it was observed that for CWR22rv1 tumor xenografts, the smaller the tumor size was, the lower was the ${ }^{18} \mathrm{~F}$-FDG uptake (unpublished data, December 2008). However, with ${ }^{18} \mathrm{~F}$-FPA even the smaller tumors $(<6 \mathrm{~mm})$ were clearly delineated as shown in Figure 2.

\section{CONCLUSION}

In the present study, we have evaluated the potential of ${ }^{18} \mathrm{~F}-\mathrm{FPA}$ as a PET tracer for imaging prostate cancer. Biodistribution and PET studies indicate that ${ }^{18} \mathrm{~F}-\mathrm{FPA}$ accumulates in the tumors and produces high tumor-tobackground ratios. In comparison with ${ }^{18} \mathrm{~F}-\mathrm{FDG},{ }^{18} \mathrm{~F}-\mathrm{FPA}$ shows better delineation of CWR22rv1 prostate cancer xenografts on PET studies. In addition, ${ }^{18} \mathrm{~F}$-FPA has a much higher \%ID/g than does acetate. These studies support our hypothesis that ${ }^{18} \mathrm{~F}-\mathrm{FPA}$ is a promising PET tracer for prostate cancer imaging, and further studies are warranted to examine if ${ }^{18} \mathrm{~F}$-FPA offers any advantages over existing tracers for prostate cancer.

\section{ACKNOWLEDGMENTS}

This work was supported in part by NIH grant P50 CA86438. Technical services provided by the MSKCC Small-Animal Imaging Core Facility, supported in part by NIH Small-Animal Imaging Research Program (SAIRP) grant R24 CA83084 and NIH grants 096945 P30 CA08748, are also gratefully acknowledged. Support from the radiochemistry and cyclotron core for production and supply of ${ }^{18} \mathrm{~F}$ is also acknowledged.

\section{REFERENCES}

1. Jemal A, Siegel R, Ward E, et al. Cancer statistics, 2008. CA Cancer J Clin. 2008;58:71-96.

2. John SS, Zietman AL, Shipley WU, Harisinghani MG. Newer imaging modalities to assist with target localization in the radiation treatment of prostate cancer and possible lymph node metastases. Int J Radiat Oncol Biol Phys. 2008; 71(1, suppl)S43-S47.

3. Bouchelouche K, Oehr P. Positron emission tomography and positron emission tomography/computerized tomography of urological malignancies: an update review. J Urol. 2008;179:34-45.

4. Matthies A, Ezziddin S, Ulrich EM, et al. Imaging of prostate cancer metastases with ${ }^{18}$ F-fluoroacetate using PET/CT. Eur J Nucl Med Mol Imaging. 2004;31:797.

5. Ponde DE, Dence CS, Oyama N, et al. ${ }^{18} \mathrm{~F}$-fluoroacetate: a potential acetate analog for prostate tumor imaging-in vivo evaluation of ${ }^{18} \mathrm{~F}$-fluoroacetate versus ${ }^{11} \mathrm{C}$-acetate. J Nucl Med. 2007;48:420-428.

6. DeGrado TR, Coleman RE, Wang S, et al. Synthesis and evaluation of ${ }^{18} \mathrm{~F}$ labeled choline as an oncologic tracer for positron emission tomography: initial findings in prostate cancer. Cancer Res. 2001;61:110-117.

7. Igerc I, Kohlfurst S, Gallowitsch HJ, et al. The value of ${ }^{18} \mathrm{~F}$-choline PET/CT in patients with elevated PSA-level and negative prostate needle biopsy for localisation of prostate cancer. Eur J Nucl Med Mol Imaging. 2008;35:976-983.

8. Vees $\mathrm{H}$, Buchegger F, Albrecht $\mathrm{S}$, et al. ${ }^{18} \mathrm{~F}$-choline and/or ${ }^{11} \mathrm{C}$-acetate positron emission tomography: detection of residual or progressive subclinical disease at very low prostate-specific antigen values $(<1 \mathrm{ng} / \mathrm{mL})$ after radical prostatectomy. BJU Int. 2007;99:1415-1420.

9. Kwee SA, DeGrado TR, Talbot JN, Gutman F, Coel MN. Cancer imaging with fluorine-18-labeled choline derivatives. Semin Nucl Med. 2007;37:420-428.

10. Veach DR, Namavari M, Pillarsetty N, et al. Synthesis and biological evaluation of a fluorine-18 derivative of dasatinib. J Med Chem. 2007;50:5853-5857.

11. Pillarsetty N, Cai S, Ageyeva L, Finn RD, Blasberg RG. Synthesis and evaluation of $\left[{ }^{18} \mathrm{~F}\right]$ labeled pyrimidine nucleosides for positron emission tomography imaging of herpes simplex virus 1 thymidine kinase gene expression. J Med Chem. 2006;49:5377-5381.

12. Pal A, Glekas A, Doubrovin M, et al. Molecular imaging of EGFR kinase activity in tumors with ${ }^{124}$ I-labeled small molecular tracer and positron emission tomography. Mol Imaging Biol. 2006;8:262-277.

13. Veach DR, Namavari M, Beresten T, et al. Synthesis and in vitro examination of $\left[{ }^{124} \mathrm{I}\right]-, \quad\left[{ }^{125} \mathrm{I}\right]-$ and $\left[{ }^{131} \mathrm{I}\right]-2$-(4-iodophenylamino) pyrido[2,3-d]pyrimidin-7-one radiolabeled Abl kinase inhibitors. Nucl Med Biol. 2005;32:313-321.

14. Lorber SH, Komarov SA, Shay H. Effect of sham feeding on gastric motor activity of the dog. Am J Physiol. 1950;162:447-451.

15. Pritchard GI, Tove SB. Interrelationships between the metabolism of short-chain fatty acids by ruminant liver slices. Biochim Biophys Acta. 1960;41:130-137.

16. Guhlke S, Coenen HH, Stocklin G. Fluoroacylation agents based on small Nca [F-18] fluorocarboxylic acids. Appl Radiat Isot. 1994;45:715-727.

17. Chan SY, Brunken RC, Phelps ME, Schelbert HR. Use of the metabolic tracer carbon-11-acetate for evaluation of regional myocardial perfusion. J Nucl Med. 1991;32:665-672.

18. Gropler RJ, Siegel BA, Geltman EM. Myocardial uptake of carbon-11-acetate as an indirect estimate of regional myocardial blood flow. J Nucl Med. 1991; 32:245-251.

19. Dimitrakopoulou-Strauss A, Strauss LG. PET imaging of prostate cancer with ${ }^{11}$ C-acetate. J Nucl Med. 2003;44:556-558.

20. Vavere AL, Kridel SJ, Wheeler FB, Lewis JS. $1{ }^{11} \mathrm{C}$-acetate as a PET radiopharmaceutical for imaging fatty acid synthase expression in prostate cancer. J Nucl Med. 2008;49:327-334.

21. Knust EJ, Kupfernagel C, Stocklin G. Long-chain F-18 fatty acids for the study of regional metabolism in heart and liver: odd-even effects of metabolism in mice. J Nucl Med. 1979;20:1170-1175.

22. Beer AJ, Haubner R, Wolf I, et al. PET-based human dosimetry of ${ }^{18}$ F-galactoRGD, a new radiotracer for imaging alpha $\mathrm{v}$ beta3 expression. J Nucl Med. 2006;47:763-769.

23. Lock EA, Gyte A, Sturgess NC, Duffell S, Wyatt I. 2-Halopropionic acidinduced cerebellar granule cell necrosis in the rat: in vivo and in vitro studies. Neurotoxicology. 2001;22:363-374.

24. Buchanan JM, Hastings AB, Nesbett FB. The role of carboxyl-labeled acetic, propionic and butyric acids in liver glycogen formation. $J$ Biol Chem. $1943 ; 150: 413-425$. 